\title{
Mifepristone and Oral Misoprostol for Early Medical Abortion
}

\author{
Shrivastava V, ${ }^{1}$ Shrivastava A \\ 'Department of Obstretics and Gynecology, Nepal Medical College Teaching Hospital, Jorpati, Nepal, ${ }^{2}$ Kathmandu, \\ Nepal.
}

\section{ABSTRACT}

Background: Combined mifepristone and misoprostol is the best method of medical termination of pregnancy. The study is undertaken to find out the success rate, acceptability, efficacy and patient satisfaction of medical abortion in pregnant women with 49 days of gestation.

Methods: The pregnant women with amenorrhea of 49 days or less seeking termination of pregnancy received were studied. The $200 \mathrm{mg}$ of oral mifepristone and followed 48 hours later with 600 microgram of oral misoprostol were given.

Results: The success rate with the regime was 47 (94\%) and 49 (98\%) were satisfied. Weakness 24 (48\%), Nausea 10 (20\%), diarrhea $12(25 \%)$, needing analgesic $4(8 \%)$ were the side effects of the combined regime.

Conclusions: Medical termination of pregnancy with combination of mifepristone and oral misoprostol has a good success rate. The side effect of the regimen in our setup is less and well accepted. Majority of the patient are satisfied with medical termination of pregnancy.

Key words: medical abortion, misoprostol, mifepristone

\section{INTRODUCTION}

The prostaglandins (PGS) are available since early 1970 s and anti progesterone in 1980s, since then medical abortion has become an alternative method of first trimester pregnancy termination. ${ }^{1}$ The most widely researched drugs used for abortion are, PGS alone, methotrexate alone, mifepristone alone, mifepristone with prostaglandins and methotrexate with prostaglandins. The most widely used regime is mifepristone with misoprostol. ${ }^{1}$

Misoprostol is a unique drug in the sense that it can be given orally, vaginally, sublingually. ${ }^{2}$ In spite of more side effects and complication with surgical termination of pregnancy, medical termination is still a preferred choice among women. ${ }^{3}$

The objective of the study is to determine the efficacy, acceptability and side effects of combined oral mifepristone and misoprostol use for termination of early pregnancy.

\section{METHODS}

A prospective cross sectional study was conducted in Norvic International Clinic from January, 2009 to June, 2009. Ethical approval and patient consent was taken. The patient with early pregnancy of 49 days or less, were included in the study. Patient with severe

Correspondence: Dr. Veena Shrivastava, Department of Obstretics and Gynecology, Nepal Medical College Teaching Hospital, Jorpati, Nepal. Phone: 9851043013, Email: veenashrivastava@gmail.com 
anemia, bronchial asthma, suspected ectopic pregnancy were excluded from the study. After history and clinical examination, gestational age was confirmed by ultrasonogram. On the first day, $200 \mathrm{mg}$ of mifepristone was given to the patient to be swallowed under supervision before $9 \mathrm{AM}$ in the morning and then was instructed not to take any food for next two hours. Later, she was advised to attend clinic after 48 hours or ingestion. Information was given on possible side effects. She was requested to write down or inform anything abnormal happening to her. On day three, 600 microgram of misoprostol (200 microgram tabs-three tabs) were given to patient to swallow. Those who were unable to come on third day were given 600 microgram (Three 200 microgram tabs) on day one to take home and swallow on third day, 48 hours after taking Mifepristone. Possible side effects were explained to the patient. The patient was requested to write down or inform anything abnormal happening to her. They were sent home after ten to fifteen minutes of observation with emergency contact number. Injection Anti $\mathrm{D}$ given, if mother in Rh negative was given. Time arranged for follow up on next day if client had only light bleeding on day three, otherwise all of them were called two weeks later. Upon following up at two weeks, patients were asked about bleeding per vagina still persisting or not. Time interval between start of vaginal bleeding and ingestion of misoprostol was noted along with duration and amount of bleeding in comparison to menstrual period was asked. Any problem regarding pain abdomen, its duration and its intensity, gastrointestinal symptoms, rise in temperature, visualization of product of conception and client satisfaction were recorded. Clinical examination and ultrasonogram was performed to confirm complete abortion.

If the patient complained of heavy bleeding or there was evidence of incomplete abortion, emergency suction evacuation was performed. Patient who had only light bleeding on day three, following swallowing of misoprostol were called back again on fourth day. If clinical examination and ultrasonogram showed evidence of retained sac or retained product of conception, then again 400 microgram of misoprostol was given orally and called back in two weeks time. In case of persistent significant bleeding at two weeks follow up without evidence of incomplete abortion either clinically or by Ultrasonogram, again 400 microgram misoprostol orally and a course of antibiotic (Ciprofloxacin and metronidazole for five days) were given. These patients were again followed up in one week and suction evacuation was performed if bleeding was still persisting.

Data collection and statistical analysis were done using Microsoft Excel 2003.

\section{RESULTS}

Total of 50 patients were taken in the study and majority of the patient were in 20-29 age groups (Table 1). Out of this $46(96 \%)$ were married and $2(4 \%)$ were unmarried.

\begin{tabular}{|lc|}
\hline \multicolumn{2}{|l|}{ Table 1. Age distribution of clients } \\
\hline Age group & Number (Percentage) \\
\hline Teenage( 19 and below) & $2(4)$ \\
$20-29$ years & $30(60)$ \\
$30-39$ years & $14(28)$ \\
$40 y r s$ and above & $4(8)$ \\
Total & $50(100)$ \\
\hline
\end{tabular}

Majority of the patients were multipara 26 (52\%), 13 (26\%) were primipara, 9 (18\%) were nulliparous and 2 (4\%) were grandmultipara (Table 2 ).

\section{Table 2. Parity distribution}

\begin{tabular}{lc|}
\hline Parity & Number (\%) \\
\hline Nulliparous & $9(18 \%)$ \\
Primipara & $13(26 \%)$ \\
Multipara & $26(52 \%)$ \\
Grandmultipara & $2(4 \%)$ \\
Total & $50(100)$ \\
\hline \hline
\end{tabular}

Out of 50 cases, 20 (40\%) were in fourth week of gestation and $21(42 \%)$ were in fifth week of gestation (Table 3 ).

Table 3. Period of gestation at the time of request for Medical Termination of Pregnancy

\begin{tabular}{|lc|}
\hline Duration of pregnancy (weeks) & Number (\%) \\
\hline 4 & $20(40)$ \\
5 & $21(42)$ \\
6 & $7(14)$ \\
7 & $2(4)$ \\
Total & $50(100)$ \\
\hline
\end{tabular}

The most common side effect with mifepristone was nausea 29 (58\%), Weakness 18 (36\%) Bleeding per vaginum10 (20\%) and loss of appetite $10(20 \%)$. Total 21 (42\%) cases had no complaints. With the combined use of mifepristone and oral misoprostol weakness 24 (48\%), Nausea 10 (20\%), diarrhea 12 (25\%), needed analgesic 4 (8\%) and in $10(20 \%)$ expulsion of Product of conception noticed (Table 4). 


\begin{tabular}{|lcc|}
\hline Table 4. Side effects of mifepristone/ & misoprostol \\
\hline Side effects & $\begin{array}{c}\text { Mifepristone } \\
(\%)\end{array}$ & $\begin{array}{c}\text { Combined } \\
\text { Mifepristone and } \\
\text { Misoprostol }\end{array}$ \\
\hline No complaints & $21(42)$ & - \\
Nausea & $29(58)$ & $10(20)$ \\
Vomiting & - & - \\
Diarrhea & - & $12(25)$ \\
Loss of appetite & $10(20)$ & - \\
Weakness & $18(36)$ & $24(48)$ \\
Headache & $4(8)$ & - \\
Rise in Temperature & - & $2(4)$ \\
Need for analgesic & - & $4(8)$ \\
$\begin{array}{l}\text { Expulsion of } \\
\text { Product of } \\
\text { conception noticed }\end{array}$ & $0(0)$ & $10(20)$ \\
\hline \hline
\end{tabular}

The success rate of medical termination of pregnancy was $47(94 \%)$. All those cases who didn't require surgical evacuation and in whom pregnancy didn't continue were considered as success (Table 5).

\begin{tabular}{ll|}
$\begin{array}{l}\text { Table 5. Outcome of medical } \\
\text { pregnancy }\end{array}$ & termination of \\
\hline & $47(94)$ \\
\hline Success & - \\
Pregnancy continued & $\%)$ \\
Requiring surgical evacuation & $3(6)$ \\
Total & $50(100)$ \\
\hline \hline
\end{tabular}

Majority of the patients were satisfied 49 (98\%) with the procedure.

\section{DISCUSSIONS}

This study had shown that Mifepristone with oral misoprostol combination was effective (94\%) method of terminating up to 49 days pregnancy. A slightly lower success rate $(91.3 \%)$ and $(87 \%)$ had been shown in similar study done in Nepal and Aberdeen. ${ }^{4,5}$ In both the studies the sample size was big and pregnancy up to 63 days pregnancy was included. The dose of misoprostol was also different. In contrast, pregnancy up to 49 days had been included in our study. The reason might be that the patients with medical termination at earlier gestational age have better outcome. However, the need for better studies in this context cannot be ruled out to verify the finding.

Among the study groups, who were given mifepristone orally on the first day had complain nausea 29 (58\%) followed by weakness 18 (36\%), bleeding per vaginum10 (20\%) and loss of appetite $10(20 \%)$. Total 21 (42\%) cases had no complaints. Studies suggest the use of mifepristone alone (150 $\mathrm{mg}$ for four days) associated with nausea and vomiting in almost half of the study patients with no significant differences in the incidences of problems that occur prior to treatment. ${ }^{6}$ Another study suggest abdominal pain, cramping, nausea, vomiting bleeding and delay in onset of next menstrual cycle with use of $200 \mathrm{mg}$ of mifepristone. ${ }^{7}$ The significant lower rate of side effects with mifepristone can be due to our observation for just only a shorter period of interval i.e. two days. Actual rate of side effects with the use of mifepristone alone requires further observation for a longer duration. Therefore further pharmacokinetics study with various dosing regimen along with longer period of follow up has to be done in order to determine the significance of the findings in our setup.

Combined use of mifepristone and misoprostol has been advocated by many studies rather than misoprostol alone. The effectiveness of using misoprostol alone compared to combined regimen rises from $65 \%$ to $95 \%$ for medical termination of prefnancy. ${ }^{8}$ The main complaints were weakness $24(48 \%)$, Nausea $10(20 \%)$, diarrhea 12 (25\%), needed analgesic 4 (8\%) and expulsion of product of conception noticed 10 (20\%). A randomized control trial in India with $200 \mathrm{mg}$ mifepristone oral and $600 \mathrm{mg}$ oral misoprostol reported nausea $25.7 \%$, vomiting $6.8 \%$, diarrhea $4.8 \%$, fever more than 38 degree $4.2 \%$ and severe abdominal pain in $5 \% .{ }^{9}$ Other study advocates nausea, headache, vomiting and gastrointestinal side effects as the potential complication of oral mifepristone and misoprostol use. ${ }^{10-12}$ The fewer rate of side effects in our study can reflect the acceptability pattern in our setup however its implication in a bigger setup is can still be speculated.

The acceptability of medical termination of pregnancy and subsequent satisfaction to the patients has been well demonstrated by various studies. ${ }^{9,13}$ Almost all patient were satisfied in our study, however the number of patient included in the study group may not be able to give the exact picture of satisfaction in our population.

As a study design was prospective, the selection of appropriate cases and appropriate sample size to delineate the precise outcome can be the limiting factor of the study.

The variation of pharmacokinetics characteristics of the drug and its efficacy in our population is another question to be answered. Therefore the generalization of the possible outcome in the population requires further better studies. 


\section{CONCLUSIONS}

Medical termination of pregnancy with use of $200 \mathrm{mg}$ oral mifepristone and 600 microgram of misoprostol with less than 49 days of pregnancy has a good success rate. The side effect of the regimen in our setup is less and well accepted. Majority of the patient are satisfied with medical termination of pregnancy.

The need regarding the appropriate dose and route of administration of misoprostol and its acceptability in the general population requires more detailed study.

\section{REFERENCES}

1. Kulier R, Gülmezoglu AM, Hofmeyr GJ, Cheng LN, Campana A. Medical methods for first trimester abortion. Cochrane Database Syst Rev. 2004;(2):CD002855.

2. Tang OS, Ho PC. The pharmacokinetics and different regimens of misoprostol in early first-trimester medical abortion. Contraception. 2006 Jul;74(1):26-30.

3. Shannon C, Wiebe E, Jacot F, Guilbert E, Dunn S, Sheldon WR et al. Regimens of misoprostol with mifepristone for early medical abortion: a randomised trial. BJOG. 2006 Jun;113(6):621-8.

4. Karki C, Pokharel H, Kushwaha A, Manandhar D, Bracken H, Winikoff B. Acceptability and feasibility of medical abortion in Nepal. J Gynaecol Obstet. 2009 Jul;106(1):39-42.

5. el-Refaey H, Rajasekar D, Abdalla M, Calder L, Templeton A. Induction of abortion with mifepristone (RU 486) and oral or vaginal misoprostol. N Engl J Med. 1995 Apr 13;332(15):983-7.
6. Cameron IT, Michie AF, Baird DT. Therapeutic abortion in early pregnancy with antiprogestogen RU486 alone or in combination with prostaglandin analogue (gemeprost). Contraception. 1986 Nov;34(5):459-68.

7. Sarkar NN. Mifepristone: bioavailability, pharmacokinetics and use-effectiveness. Eur J Obstet Gynecol Reprod Biol. 2002 Mar 10;101(2):113-20.

8. Donaldson K, Briggs J, McMaster D. RU 486: an alternative to surgical abortion. J Obstet Gynecol Neonatal Nurs. 1994 Sep;23(7):555-9.

9. A multicentre randomized comparative clinical trial of $200 \mathrm{mg}$ RU486 (mifepristone) single dose followed by either $5 \mathrm{mg} 9$ methylene PGE(2) gel (meteneprost) or 600 microg oral PGE(1) (misoprostol) for termination of early pregnancy within 28 days of missed menstrual period. ICMR Task Force Study. Indian Council of Medical Research. Contraception. 2000 Sep;62(3):125-30.

10. Preference and acceptability of oral versus vaginal administration of misoprostol in medical abortion with mifepristone. Eur J Obstet Gynecol Reprod Biol. 2005 Nov 1;123(1):87-91.

11. Kulier R, Gülmezoglu AM, Hofmeyr GJ, Cheng LN, Campana A. Medical methods for first trimester abortion. Cochrane Database Syst Rev. 2004;(2):CD002855

12. Zhonghua Fu Chan Ke Za Zhi. [Termination of early pregnancy using RU 486 alone or in combination with prostaglandin. The RU 486 Collaboration Group] 1990 Jan;25(1):31-4, 62.

13. Karki C, Pokharel H, Kushwaha A, Manandhar D, Bracken H, Winikoff B. Acceptability and feasibility of medical abortion in Nepal. Int J Gynaecol Obstet. 2009 Jul;106(1):39-42. 